\title{
Uso do Orto-Ftalato de Sódio na reduçáo da concentraçáo de cromo no efluente de curtumes
}

\section{Use of sodium ortho-phthalate in reducing the concentration of chromium in tannery effluent}

Ricardo de Lima Lacerda ${ }^{1}$

\section{Resumo}

O resíduo de cromo proveniente do processo de curtimento de couros consiste em um dos principais problemas ambientais das indústrias de curtume. Muitas são as tentativas de minimizar a produção de tais resíduos. O presente trabalho tem por objetivo avaliar o uso de orto-ftalato de sódio na redução da concentração do cromo no efluente de curtumes, tornando possível uma futura ferramenta para ensino de práticas sustentáveis aos profissionais dessa indústria. $\mathrm{O}$ experimento foi realizado comparando a concentração de $\mathrm{Cr}_{2} \mathrm{O}_{3}$ dos banhos residuais do processo convencional de curtimento ao cromo (média de 4,59g/l) e o processo experimental (média de $1,87 \mathrm{~g} / \mathrm{l})$. Como resultado, obtivemos uma substancial diminuição do referido resíduo $(59,26 \%)$ através de uma maior fixação desse metal no substrato dérmico. Concluímos que o uso do orto-ftalato de sódio é efetivo para o propósito de redução das concentraçóes de cromo no efluente de curtumes e estamos desenvolvendo um produto comercial para aplicação com esse fim.

Palavras-chave: Cromo, Curtimento, Efluente, Resíduo

\section{Abstract}

The residual chromium from the leather tanning process is one of the main environmental problems of this type of industry. Many are the attempts to minimize the production of such waste. This study aims to evaluate the use of sodium ortho-phthalate in reducing the concentration of chromium in effluents, making possible a future tool for teaching sustainable practices to professionals in this industry. The experiment was performed comparing the concentration of $\mathrm{Cr}_{2} \mathrm{O}_{3}$ baths residual in conventional chromium tanning (average $4.59 \mathrm{~g} / \mathrm{l}$ ) and the experimental process (average $1.87 \mathrm{~g} /$ l). As a result, we achieved a substantial reduction of this residue (59.26\%) through increased fixation of the metal in dermal substrate. We conclude that the use of ortho-phthalate sodium is effective for this purpose and are developing a commercial product for application to this effect.

Keywords: Chromium, leather tanning, effluent, waste. 


\section{INTRODUÇÃO}

O Brasil possui um relevante papel no segmento do couro, pois é o maior produtor e exportador de couros do mundo, com processamento anual na faixa de 44 milhóes de unidades e faturamento estimado em U\$2,5 bilhóes (CICB, 2007) ${ }^{1}$.

Todas essas peles passam por um processo industrial denominado "curtimento".

O curtimento consiste na transformação das peles em material estável e imputrescível. Com o curtimento ocorre o fenômeno de reticulação por efeito de diferentes agentes empregados. Pela reticulação, resulta aumento da estabilidade de todo o sistema colágeno, o que pode ser evidenciado pela determinação da temperatura de retração (HOINACKI, 1978) ${ }^{2}$.

As características mais importantes conferidas pelo curtimento, como o aumento da temperatura de retraçáo, a estabilização face às enzimas e a diminuição da capacidade de intumescimento do colágeno, bem como a estrutura revelada ao microscópio eletrônico, são justificadas pela teoria da estabilização da proteína da pele, através da formação de enlaces transversais (HOINACKI, 1978)22.

Os produtos químicos utilizados nesse processo são denominados "curtentes".

Os curtentes empregados na fabricação de couros podem ser divididos em três grupos principais de acordo com sua constituição química: Curtentes poliaromáticos, curtentes minerais e curtentes alifáticos (BASF, 1995) ${ }^{3}$.

Curte-se atualmente entre $80 \%$ e $90 \%$ das peles para vestuário e para sapato com produtos de cromo. Os couros ao cromo são fáceis de fabricar com um mínimo de tempo, leves e sólidos à luz, fáceis de tingir, de acabar e de trabalhar na indústria do calçado (BAYER, 1954) ${ }^{4}$.

Atualmente é grande o número de pesquisas na intenção de eliminar ou minimizar o uso do cromo devido às dúvidas que esse composto ainda desperta quanto à sua segurança.

De acordo com a Organização Mundial de Saúde (1996), a presença de cromo no solo é freqüentemente resultante da atividade humana. $\mathrm{O}$ cromo de valência (VI) ou hexavalente, é mais extensamente absorvido pelo trato gastrointestinal, penetra facilmente na membrana da célula, é teratogênico, mutagênico e cancerígeno, enquanto o cromo de valência (III) ou trivalente, que é o utilizado nas indústrias de curtumes, não apresenta tais características, embora seja também cumulativo tanto quanto o hexavalente.

Atualmente, o uso dos sais de cromo para o curtimento de couros é cada vez mais questionado, tendo em vista os possíveis efeitos danosos que pode ocasionar à saúde e ao meio ambiente. A possibilidade da conversão do cromo
(III) presente no couro para o cromo (VI) faz com que todo material contendo esse metal, tais como efluentes líquidos, estejam sujeitos a uma rigorosa legislação quanto ao seu tratamento e disposição final (GONÇALVES, 2007)5.

A princípio, devido aos efeitos na saúde serem determinados pela valência do cromo, diretrizes diferentes para valores de cromo (III) e (VI) deveriam ser tomadas. Entretanto, métodos analíticos atuais favorecem limites para o cromo total, até que informaçôes adicionais estejam disponíveis e o cromo possa ser reavaliado (OMS, 1996)6.

A utilizaçáo dos sais de cromo no curtimento gera resíduos sólidos e efluentes líquidos com presença de cromo trivalente. $\mathrm{O}$ efluente líquido consiste no banho residual de curtimento. Para reduzir o teor de cromo no efluente, a otimização do processo de curtimento em termo de oferta de óxido de cromo é uma possibilidade. Além disso, existem no mercado alguns produtos que provocam a modificação no sal de cromo ou na fibra de colágeno, aumentando a reatividade entre eles, com isso melhorando a fixação e conseqüentemente o esgotamento dos banhos (GONÇALVES, 2007) 5 .

Nesse contexto, o objetivo desse trabalho é testar o uso do orto-ftalato de sódio na tentativa de diminuir a concentração de cromo do efluente de curtumes, tornando possível uma futura ferramenta para ensino de práticas sustentáveis aos profissionais de curtume.

\section{MATERIAIS E MÉTODOS}

O estudo foi realizado em uma indústria curtidora localizada no município de Juazeiro-BA. A empresa é um curtume de porte médio com produção diária de 1000 peles por dia (bovinos) e 8000 peles por dia (entre caprinos e ovinos).

Os testes foram realizados no período de 29 de Junho a 24 de Julho de 2009 apenas em peles bovinas integrais. Analisamos 20 partidas da produção, cada partida contendo 400 peles, sendo que em 10 delas foi usado o processo normal do Curtume e nas outras 10 partidas apenas adicionamos no final do processo o produto a ser investigado, sem qualquer outra alteração, de modo a evitar vieses.

As fórmulas utilizadas tiveram suas porcentagens baseadas no peso em tripa, como seguem: 
Tabela 1: Fórmula padráo do curtume.

\begin{tabular}{|c|c|c|c|}
\hline$\%$ & Produto & Tempo & Observaçáo \\
\hline 60 & Água & $20 \mathrm{~min}$ & \\
\hline 6 & Sal & $20 \mathrm{~min}$ & $\mathrm{pH} 2,0$ \\
\hline 0,4 & Ácido Fórmico & $1 \mathrm{~h}$ & Corte atravessado \\
\hline 0,7 & Ácido Sulfúrico & $4 \mathrm{~h}$ & \\
\hline 7 & Sal Básico de Cromo & $5 \mathrm{~min}$ & Áquecimento até $50 \mathrm{oC}$ \\
\hline 60 & Água 45oC & $+\mathrm{h}$ & $\mathrm{pH} 3,8$ \\
\hline 0,7 & Óxido de Magnésio & $2 \mathrm{~h}$ & Descarregar / Lavar \\
\hline 0,1 & Fungicida & Descarregar / Lavar \\
\hline
\end{tabular}

Tabela 2: Fórmula Proposta.

\begin{tabular}{|c|c|c|c|}
\hline$\%$ & Produto & Tempo & Observação \\
\hline 60 & Água & & \\
\hline 6 & Sal & $20 \mathrm{~min}$ & \\
\hline 0,4 & Ácido Fórmico & $20 \mathrm{~min}$ & \\
\hline 0,7 & Ácido Sulfúrico & $1 \mathrm{~h}$ & $\mathrm{pH} 2,0$ \\
\hline 7 & Sal Básico de Cromo & $4 h$ & Corte atravessado \\
\hline 60 & Água 45 oC & $5 \mathrm{~min}$ & \\
\hline \multirow[t]{2}{*}{0,7} & Óxido de Magnésio & $2 \mathrm{~h}$ & \\
\hline & & $+4 h$ & Aquecimento até $50 \mathrm{oC}$ \\
\hline 0,1 & Fungicida & & \\
\hline 0,7 & Orto-Ftalato de Sódio & $2 \mathrm{~h}$ & $\mathrm{pH} 4,0$ \\
\hline & & & Descarregar / Lavar \\
\hline
\end{tabular}

\section{RESULTADOS}

As análises das concentraçôes de cromo residual nos banhos de curtimento, foram feitas no próprio laboratório do Curtume e seguiram as normas da Associação Brasileira de Normas Técnicas (ABNT, NBR 13335). 
Tabela 3: Resultados obtidos

\begin{tabular}{|c|c|c|c|c|}
\hline Data & Fuláo & Identificação & $\mathbf{p H}$ & $\begin{array}{c}\text { Cromo (Cr2O3) } \\
\text { em g/l }\end{array}$ \\
\hline $29 / 06 / 2009$ & 1 & Padrão & 4 & 5,63 \\
\hline $30 / 06 / 2009$ & 1 & Teste & 4,01 & 1,89 \\
\hline $01 / 07 / 2009$ & 3 & Padrão & 3,89 & 5,48 \\
\hline $02 / 07 / 2009$ & 1 & Teste & 3,92 & 2 \\
\hline $03 / 07 / 2009$ & 1 & Padrão & 3,83 & 4,77 \\
\hline $06 / 07 / 2009$ & 1 & Teste & 4,11 & 1,79 \\
\hline $07 / 07 / 2009$ & 2 & Padrão & 3,79 & 4,22 \\
\hline $08 / 07 / 2009$ & 5 & Teste & 4,04 & 1,84 \\
\hline $09 / 07 / 2009$ & 5 & Padrão & 4,38 & 2,85 \\
\hline $10 / 07 / 2009$ & 5 & Teste & 4,22 & 1,72 \\
\hline $13 / 07 / 2009$ & 5 & Padrão & 4,01 & 5,2 \\
\hline $14 / 07 / 2009$ & 1 & Teste & 3,94 & 1,92 \\
\hline $15 / 07 / 2009$ & 1 & Padrão & 4,05 & 4,41 \\
\hline $16 / 07 / 2009$ & 1 & Teste & 4,21 & 1,77 \\
\hline $17 / 07 / 2009$ & 1 & Padrão & 4,07 & 4,01 \\
\hline $20 / 07 / 2009$ & 4 & Teste & 4,12 & 1,75 \\
\hline $21 / 07 / 2009$ & 1 & Padrão & 4,01 & 4,95 \\
\hline $22 / 07 / 2009$ & 1 & Teste & 4,18 & 1,88 \\
\hline $23 / 07 / 2009$ & 1 & Padrão & 4,03 & 4,41 \\
\hline $24 / 07 / 2009$ & 1 & Teste & 4,01 & 2,11 \\
\hline
\end{tabular}

\section{DISCUSSÃO}

A análise dos dados mostra uma média de concentração de cromo de $4,59 \mathrm{~g} / \mathrm{l}$ no procedimento padrão e de $1,87 \mathrm{~g} / \mathrm{l}$ no procedimento teste, o que significa uma redução de $59,26 \%$, ou seja, no processo testado, sobrou bem menos que a metade de resíduos poluentes no final da produção.

\section{Gráfico 1: Valores de concentraçáo de cromo no banho final do curtimento.}

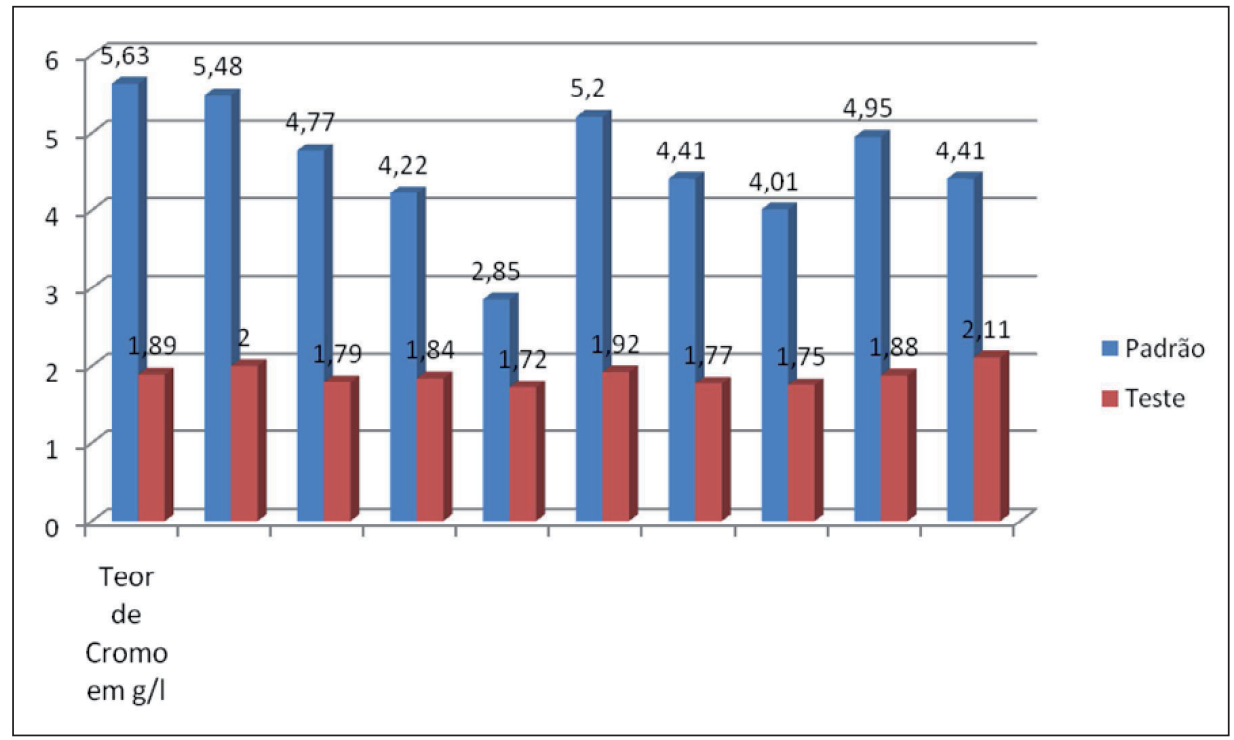




\section{CONCLUSÃO}

O uso do orto-ftalato de sódio foi bastante útil na reduçáo das concentraçóes de cromo nos banhos de curtimento, e conseqüentemente no efluente do curtume, porém deve-se realizar testes em maior escala para se quantificar com mais precisão essa diferença.

É importante salientar que não houve correlaçáo significativa entre a concentração de cromo no banho e o pH final, porém, devido a pequena amostra, não consideraremos esse parecer como definitivo.

Sugerimos para futuros testes, fazer também a análise da quantidade de cromo fixado no couro, pois esse valor deverá subir bastante visto que se reduziram os resíduos de cromo na água, logo a quantidade de cromo fixada deve ter aumentado. Essa diferença deve ser quantificada.

Concluímos com esse trabalho que o uso do ortoftalato de sódio reduz significativamente a concentraçáo de cromo, considerado um poluente, nos efluentes de curtume e estamos desenvolvendo um produto com base nessa substância para comercialização.

\section{REFERÊNCIAS}

1- CICB - Centro das indústrias de Curtumes do Brasil. Disponível em <www.brazilianleather.com.br> Acessado em 17/08/2009.

2-Hoinacki, E; Gutheil, Nelson. Peles e Couros: origens, defeitos e industrializaçáo, 1.ed. Porto Alegre: SENAI, 1978.

3-Vademécum Para el Técnico en Curtición. Ludwigshanfen: BASF, 1995.

4-Bayer. Compostos de Cromo, MANUAL sobre a fabricaçáo, propriedades e aplicaçóes dos produtos de cromo mais usados. Leverkunsen: BAYER, 1954.

5-Gonçalves, E. Efeito de Diferentes Curtentes Sobre as Propriedades de Couros Isentos de Cromo. 2007. Dissertação (Mestrado em Qualidade Ambiental) - Programa de Pós Graduação em Gestão Tecnológica, Feevale, Novo Endereço para Correspondência: Hamburgo.

6-Chromium in Drinking-Water, Guidelines for DrinkingRicardo de Lima Lacerda ricardo_lacerda@bol.com.br water Quality. 2.ed. vol.2. Health Criteria and other supporting information. World Health Organization. Geneva, 1996. 